\title{
Health Monitoring of Nuclear Structure Containment Using Strain Gauges to Assess the Integrity
}

\author{
A. K. Parande, ${ }^{1,2}$ J. Kennedy, ${ }^{1}$ M. S. Karthikeyan, ${ }^{1}$ R. Jeyaram, ${ }^{1}$ A. Sivashanmugam, ${ }^{1}$ \\ R. H. Suresh Bapu, ${ }^{1}$ and N. Palaniswamy ${ }^{1}$ \\ ${ }^{1}$ Central Electrochemical Research Institute (CSIR), Karaikudi, Tamil Nadu 630006, India \\ ${ }^{2}$ Central Food Technological Research Institute (CSIR), Mysore, Karnataka 570020, India
}

Correspondence should be addressed to A. K. Parande; corrparande@yahoo.co.in

Received 3 June 2013; Accepted 27 June 2013

Academic Editors: S. Barakat, T. Bilir, and C. Chalioris

Copyright (C) 2013 A. K. Parande et al. This is an open access article distributed under the Creative Commons Attribution License, which permits unrestricted use, distribution, and reproduction in any medium, provided the original work is properly cited.

Assessment of concrete structures and prediction of their health and life could be possible by online monitoring of the stress/strain level and is an intelligent tool to prevent accidents. Measuring strain pattern on structures is vital to evaluate the health of forced members. The present paper describes the methodology, instrumentation line up, and coding for LabVIEW software for continuous online strain data acquisition of structures for nuclear structures. The performance of strain gauges on concrete and steel containment structures of nuclear reactor and to assess the integrity and health of the containment structure is emphases in this research paper.

\section{Introduction}

Forced structures, commonly manifested as steel frame structures, reinforcement rods, concrete containments, reinforced concrete beams, prestressed tendons in cement grout, and so forth are subjected to strain due to several loading patterns [1]. Strain is an important criterion which directly governs the service life of structures, and a careful measurement and monitoring of strain induced in forced structures can be used to predict the failure and service life of them. Structures are subjected to a variety of loading patterns which induces different stress patterns on structures according to the type of service conditions that they are subjected to. Temperature variations occur on structures resulting from exposure to sunlight or operational surroundings and nonuniform dissipation of the absorbed heat $[2,3]$ induces stress. High level of temperature variations may ultimately lead to failure [4]. Naturally, the effect of temperature on the design of containment structures is of major concern particularly in terms of compressive strength, thermal expansion, and longterm deformation under load (creep) [5].

Measurement of stress/strain levels on structures by continuous or online monitoring helps to predict life span of structures and to prevent accidents due to excess loading
$[6,7]$. Concrete structures are highly sensitive to dynamic loads and exhibit weak resistance to tensile load [8]. Direct measurement of strain under trivial conditions such as earthquake, impact loading, and vibration is not possible. Strain gauges are commonly used as sensors to assess deformation and deflection of structures $[8,9]$. Strain gauges are low noise output devices, which need well-insulated low resistance leads. Installation of strain gauges and strain measurement on structures is an art which requires special expertise. While considering the ease of installation and good sensitivity, foil-type strain gauges are normally employed. Considerable amount of work has been carried out on various aspects of strain measurements on structures; however, measurement of strain under different special environments is not well reported. This communication comprehensively presents the methodology, instrumentation, and analysis of stress levels on forced members employing laboratory testing and being extended to onsite evaluation of stress level on steel and concrete containments of nuclear reactors through the online monitoring and the assessment of their health.

The existing literature says that, however, the use of piezoelectric material lead zirconate titanate (PZT) as sensors placed in nonaccessible reinforced concrete members for the detection of damages, the assessment of their severity 
level, and even more the online monitoring of the possible damage evolution with time [10]. In another paper, studied by the same author, the potential of the detection of flexural damage state in the lower part of the midspan area of a simply supported reinforced concrete beam using piezoelectric sensors is analytically investigated [11]. The problem of comparing two different smart damping techniques using the numerical modelling of the electromechanical impedance for plate structures with piezoelectric sensors is addressed [12].

\section{Experimental}

2.1. Selection and Installation of Strain Gauges. Most of the structures are monitored by conventional strain gauges and the gauges are based on the working of the electrical signal [9]. The universally acceptable method is the Wheatstone bridge circuit method [13-18]. Installation of strain gauges on the concrete/steel surface has been carried out in accordance with ASTM standard (E1237-93; 2003-standard guide for installing bonded resistance strain gauges) and the manufacturer's recommendations [19].

The installation of strain gauge involves selection of locations, preparation of surface, and fixing. The selected surface is scratched and degreased and the strain gauges are fixed with suitable adhesive. Surface preparation ensures healthy bonding of strain gauge. Specific adhesives are used for steel and concrete surfaces. Adhesive plays a vital role in transferring energy from the surface to the strain gauge and assuring firm bonding between the two surfaces. It also fills up the pores in concrete and provides better linkage. CyanoAcrylate (TML, Japan), which has quick setting property, is a suitable adhesive for steel surfaces, while epoxy-based adhesives (P-2 TML) can be employed for concrete structures. Because, at the time of concrete cracking, the possibility of the detachment of strain gauges from the structure is high. The epoxy-based-two component adhesives ensure good adhesion of strain gauges to the concrete surface [20,21].

Foil-type strain gauges of model no. KFG-10-120-C1-11 (KYOWA, Japan) of resistance $120 \mathrm{ohms}$ with gauge factor (G.F) 2.09 were used for laboratory measurement of concrete members.

Strain gauges model no. FLA-6-11 and PL-120-11 (TML, Japan) of resistance $120 \mathrm{ohms}$ with gauge factor 2.13 were used for steel surface at containment dome and concrete containment surface, respectively.

2.2. Data Acquisition. Data acquisition (DAQ) is a continuous recording of signals from the installed strain gauges for the structural health monitoring and evaluation. It may be periodic or an online measurement. DAQ system comprises three major sections, such as hardware for data measurement and logging, and communication linkage to the computer (PC), embedded software interface. Data measurement unit may be as simple as a multimeter or a sophisticated instrumentation for continuous measurement. Special instrumentations are preferred for online measurements. The communication linkage employs either traditional analog signal interface sensors with distributed process control system or

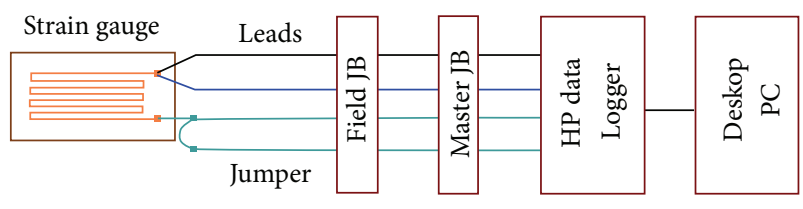

FIGURE 1: Schematic diagram of online strain measurement.

the relatively simple and modern digital networks called field-buses and ethernet chord [22]. Modern DAQ system uses ethernet interface, that is, internet protocol (TCP/IP) protocol communication or a serial communication (RS-232) with the computer.

2.3. Strain Measurement. National instruments (NI) DAQ card with NI LabVIEW software interface was used for measuring stain values of concrete members in laboratory experiments. For onsite, Hewlett Packard 34970A DAQ card, coupled with field point modules (NI make), was employed for the measurement of strain on steel/concrete surfaces. The scheme of strain measurement instrumentation is presented in Figure 1.

The specifications of the instrumentations are as follows:

(1) Name and make: FieldPoint modules, national instruments.

Card name: FieldPoint strain gauge module (NI FPSG-140) as follows:

(i) 15,60 , or $240 \mathrm{~Hz}$ filters, software configurable per channel;

(ii) 16-bit resolution, 8 channels;

(iii) $2.5,5$, or $10 \mathrm{~V}$ excitation levels, software configurable per channel.

Controller: FieldPoint ethernet controller (NI FP2000) as follows:

(i) Stand-alone embedded real-time controller or Ethernet interface for PC-based distributed I/O;

(ii) 16-MB onboard DRAM memory, $32 \mathrm{MB}$ ROM;

(iii) Advanced control, data logging, and signal processing capabilities.

(2) Name and make: 34970A data acquisition/switch unit, Hewlett Packard.

Card Name: Agilent 34902A, 16 Channel, Reed Multiplexer module.

22-bit resolution, 8 channels ( 4 wires) or 16 channels (2 wires).

Onsite measurements use HP-Benchlink software version 1.1, while the laboratory measurement coding was developed using NI LabVIEW software version 7.0. 
The algorithm developed for the software coding for strain measurement is explained below.

(1) Development of server VI by Lab-VIEW real time for the strain measurement.

(a) Coding for retrieval of data from DAQ card through FieldPoint module was done.

(b) Coding was done to communicate the measured data with time stamp using TCP/IP port to the PC.

(2) Coding for Client VI by the LabVIEW software.

(a) Coding for data retrieval from the TCP/IP port was done.

(b) Coding was done for the conversion of the measured resistance values to the microstrain.

(c) Provide the user interface and display in the Client VI such as graphs, strain data and time stamp.

(3) Strain data managing coding by LabVIEW data logging and supervisory control (DSC) coding are as follows.

(a) Coding was done for continuous data storage in citadel data base and spread-sheet file.

(b) Data storing to provide the tag information for the specific strain gauge was done.

(c) Historical trend view program was simply modified for the specific strain gauge. The main VI of historical view was inbuilt and supplied by the NI LabVIEW. Configuration of hardware was carried out after coding followed by running the VI program. The following steps were involved to run the VI program.

(1) Wiring:

strain gauge leads were connected to DAQ card.

(2) Configuration of DAQ in PC:

(a) power on and connect the Field point to the PC by ethernet cable;

(b) by using LabVIEW-measurement automation explorer (MAX) the FieldPoint modules targets were configured for communication;

(c) by MAX corresponding DAQ card channel was configured such as bridge circuit and excitation voltage.

(3) Running the program:

(a) download and run the Server VI to the FieldPoint modules;

(b) run the Server VI in personal computer.

By running both the Server VI and Client VI, the measurements were recorded online by the NI-DAQ card (FieldPoint modules) and software (LabVIEW) from the strain gauge.

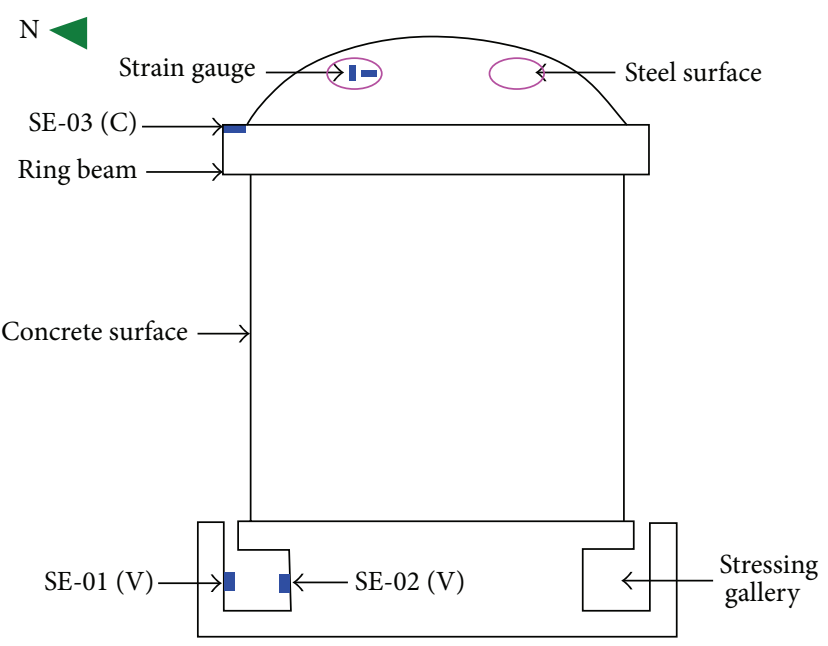

FIGURE 2: Schematic layout of strain gauge installations on containment structures.

2.4. Onsite Strain Measurement. Nuclear reactor containment is one of the critical structures in nuclear power plants. These containment structures are subjected to internal leak proof tests before its commissioning. They are subjected to high pressure. The strain measurement of concrete and steel containment structures during these tests is very vital to ensure the integrity of the structure and assess their health for the safety operation of nuclear reactor. Methodology, field worthiness, installation and online measurement of strain induced on concrete structures employing foil type strain gauges have been ascertained at laboratory testing. The use of these strain gauges for onsite measurement of strain of concrete and steel containment structures has been envisaged to assess their health. A set of strain gauges ( 9 nos.) was installed on identified locations and labelled from SE-01 to SE-09. Three gauges, namely, SE-01 to 03 were employed to measure the strain on concrete containment, and the gauges SE-04 to 09 were fixed on steel containment. The gauges were linked to the field point modules and HP data logger. The schematic layout of the strain gauges and their locations at the containment is shown in the Figures 2 and 3. The strain gauge readings were continuously recorded for 9 days and 10 minutes interval.

Four wire resistance techniques were adopted for the measurement of resistance values of strain gauges. Microstrain induced in the structure can be calculated from the following relationship:

$$
\mu \varepsilon=\left[\frac{\left(\left(R \sim R_{o}\right) / R\right)}{\text { Gauge factor }}\right] 10^{6},
$$

where $\mu \varepsilon$ is the micro strain, $\left(R \sim R_{o}\right)$ is the change in resistance in ohms, $R$ is the initial resistance in ohms, $R_{o}$ is the observed resistance in ohms, and Gauge factor is the a constant given by the manufacturer.

2.5. Measurements Schedule. Integrated leakage rate test (ILRT)/proof test was conducted for 7 days, continuous 


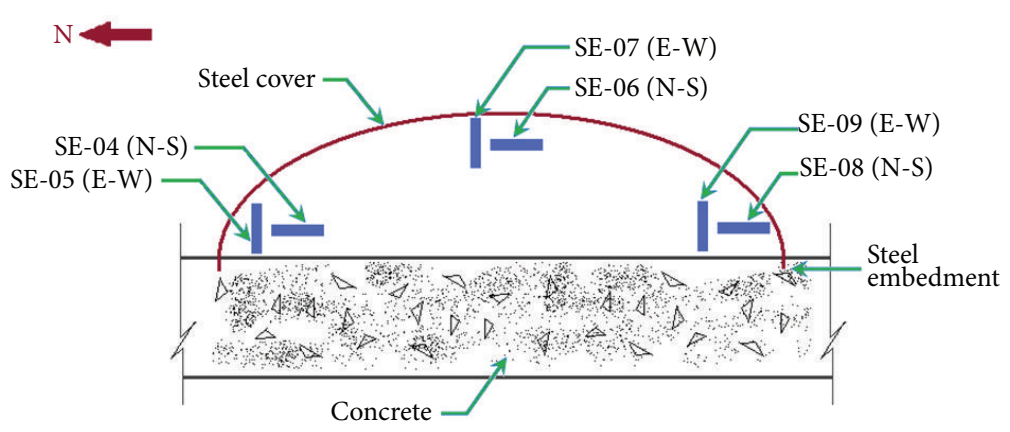

FIGURE 3: Illustration of installed strain gauge in steel surface.

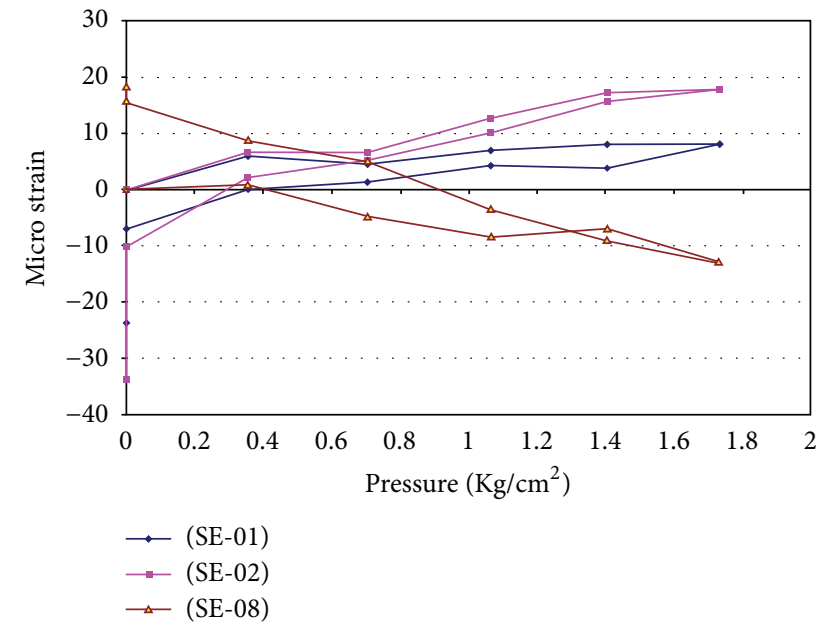

Figure 4: Micro strain of SMER's (SE-01, SE-02 \& SE-08) during ILRT.

monitoring of measurement was recorded at an interval of 10 minutes. The chronological events of ILRT proof test are shown in the Table 1.

\section{Results and Discussion}

\subsection{ILRT Results}

3.1.1. Concrete SMER's at Stressing Gallery. The proof test conducted for nuclear reactor containment is shown in Figure 4. The SMER's for concrete surface installed in stressing gallery is as follows: SE-01, SE-02, and SE-08. From the figure it is observed that the maximum micro strain value reached during the pressure at $1.73 \mathrm{~kg} / \mathrm{cm}^{2}$ was $8 \mu \varepsilon$ and gradually decreased to a value of $-7.0 \mu \varepsilon$ for SE-01 at 0 pressure level. Similarly the maximum micro strain values for SE-02 and SE08 were $17.7 \mu \varepsilon$ and $-13.0 \mu \varepsilon$, respectively, for the pressure at $1.73 \mathrm{~kg} / \mathrm{cm}^{2}$, and minimum microstrain values were $-10.1 \mu \varepsilon$ and $15.6 \mu \varepsilon$ at the pressure $0.0 \mathrm{~kg} / \mathrm{cm}^{2}$. The reading was also recorded after $24 \mathrm{hr}$. From the figure it is evident that SMER's response was good. The performances of the various sensors were satisfactory, and the subsequent data analysis showed that the containment structure response was elastic during
TABLE 1: Chronological events of proof test and ILRT.

\begin{tabular}{|c|c|}
\hline Sl. no. & Activity \\
\hline 1 & Zero run-up test started after RB box up for PC ILRT \\
\hline 2 & Pressurization started \\
\hline 3 & Pressure reached at $0.35 \mathrm{~kg} / \mathrm{cm}^{2}(\mathrm{~g})$ \\
\hline 4 & $\begin{array}{l}\text { Pressurization started after temp stabilisation and } \\
\text { rundown at } 0.35 \mathrm{~kg} / \mathrm{cm}^{2}(\mathrm{~g})\end{array}$ \\
\hline 5 & Pressure reached at $0.7 \mathrm{~kg} / \mathrm{cm}^{2}(\mathrm{~g})$ \\
\hline 6 & $\begin{array}{l}\text { Pressurization started after temp stabilisation and } \\
\text { rundown at } 0.7 \mathrm{~kg} / \mathrm{cm}^{2}(\mathrm{~g})\end{array}$ \\
\hline 7 & Pressure reached at $1.06 \mathrm{~kg} / \mathrm{cm}^{2}(\mathrm{~g})$ \\
\hline 8 & $\begin{array}{l}\text { Pressurization started after temp stabilisation and } \\
\text { rundown at } 1.06 \mathrm{~kg} / \mathrm{cm}^{2}(\mathrm{~g})\end{array}$ \\
\hline 9 & Pressure reached at $1.4 \mathrm{~kg} / \mathrm{cm}^{2}(\mathrm{~g})$ \\
\hline 10 & $\begin{array}{l}\text { Pressurization started after pressure stabilisation and } \\
\text { strain/deflection data collection }\end{array}$ \\
\hline 11 & Pressure reached $-1.73 \mathrm{~kg} / \mathrm{cm}^{2}(\mathrm{~g})$ \\
\hline 12 & $\begin{array}{l}\text { Depressurization started after pressure stabilisation and } \\
\text { strain/deflection data collection }\end{array}$ \\
\hline 13 & Pressure reached $-1.4 \mathrm{~kg} / \mathrm{cm}^{2}(\mathrm{~g})$ \\
\hline 14 & $\begin{array}{l}\text { Depressurization started after pressure stabilisation and } \\
\text { strain/deflection data collection }\end{array}$ \\
\hline 15 & Pressure reached $-1.06 \mathrm{~kg} / \mathrm{cm}^{2}(\mathrm{~g})$ \\
\hline 16 & $\begin{array}{l}\text { Depressurization started after temp stabilisation, } \\
\text { rundown and superimposition test at } 1.06 \mathrm{~kg} / \mathrm{cm}^{2}(\mathrm{~g})\end{array}$ \\
\hline 17 & Pressure reached $-0.7 \mathrm{~kg} / \mathrm{cm}^{2}(\mathrm{~g})$ \\
\hline 18 & $\begin{array}{l}\text { Depressurization started after temp stabilisation and } \\
\text { rundown at } 0.7 \mathrm{~kg} / \mathrm{cm}^{2}(\mathrm{~g})\end{array}$ \\
\hline 19 & Pressure reached $-0.35 \mathrm{~kg} / \mathrm{cm}^{2}(\mathrm{~g})$ \\
\hline
\end{tabular}

the loading and unloading stages, and the test results were found to be in reasonable agreement.

3.1.2. Concrete SMER at Ring Beam. Figure 5 shows the SMER for concrete surface installed in stressing gallery (SE25). From the figure, it is observed that the maximum microstrain values reached during the pressure at $1.73 \mathrm{~kg} / \mathrm{cm}^{2}$ were $-28.1 \mu \varepsilon$ and gradually decreased to $24.1 \mu \varepsilon$. The values obtained for the SMER installed in concrete surface depict clearly the dip below the axis and gradually increase to 


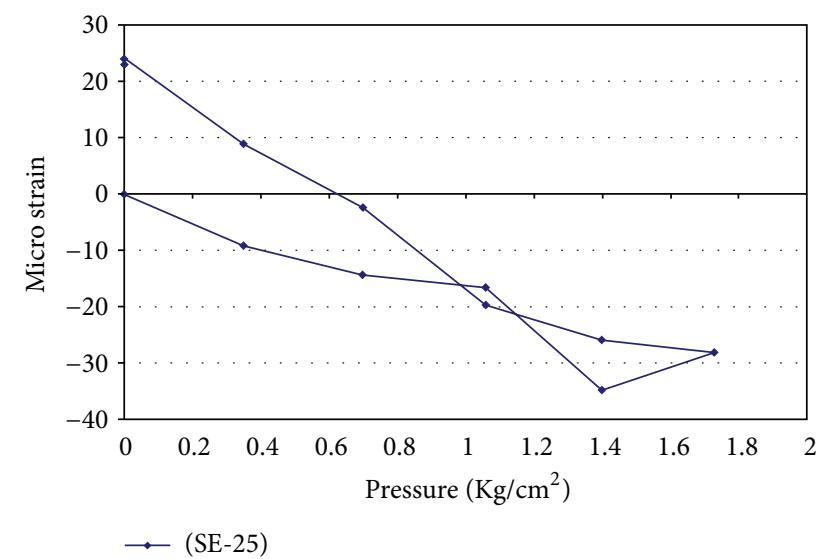

FIGURE 5: Micro strain of SMER (SE-25) during ILRT.

the positive side. The response of the SMER was found as that of the previous SMER. As the pressure test for the containment was in progress, the micro stain values also increased during pressuring and gradually decreased in depressurization. The containment structure response was elastic during the pressuring and depressurization stages, and the test results were found to be in sensible agreement.

3.1.3. Steel SMER's at Dome. Figure 6 shows the SMER's for the steel surface installed in the dome and labelled as SE55, SE-56 and SE-57. From the figure, it is evident that the maximum micro strain values reached during the pressure at $1.73 \mathrm{~kg} / \mathrm{cm}^{2}$ were $102.7 \mu \varepsilon, 38.6 \mu \varepsilon$, and $20.8 \mu \varepsilon$. Minimum microstrain values were $-8.1 \mu \varepsilon,-4.5 \mu \varepsilon$, and $-5.2 \mu \varepsilon$ that were observed after stabilization of $0 \mathrm{Kg} / \mathrm{cm}^{2}$ pressure. The stabilization reading after $24 \mathrm{hrs}$ is shown in the Table 3 . There is no much change in the microstrain values. From the figure, it is evident that all the steel SMER's response was found to be intact with the steel surface throughout the proof test. Hence, from the test it can be concluded that the response of the steel SMER's was found to be satisfactory.

3.1.4. Steel SMER's at Dome. Figure 7 shows the SMER for the steel surface installed in the dome (SG) and labelled as SE58, SE-59, and SE-60. From the figure it is evident that the maximum microstrain values reach were during the pressure at $1.73 \mathrm{~kg} / \mathrm{cm}^{2}$ was $34.8 \mu \varepsilon, 97.5 \mu \varepsilon$, and $33.9 \mu \varepsilon$. Minimum micro strain values were $-7.2 \mu \varepsilon,-1.2 \mu \varepsilon$, and $-4.5 \mu \varepsilon$ that were observed after stabilization of pressure $0.0 \mathrm{Kg} / \mathrm{cm}^{2}$. Stabilization reading after $24 \mathrm{hrs}$ shows that there is no much change in the values of micro strain, is similar to that of pressure $0 \mathrm{~kg} / \mathrm{cm}^{2}$, and can be inferred as in Table 3 . It is evident that all the steel SMER response was found to be intact with the steel surface throughout the proof test. Hence, from the test it can be concluded that the response of the steel SMER's was found to be satisfactory.

Table 2 shows the pressure up reading, and Table 3 shows the pressure down reading. From Table 2 the strain measurements for steel SMER are for nuclear reactor containment for the pressure test from 0.0 to $1.73 \mathrm{~kg} / \mathrm{cm}^{2}$. The micro stain

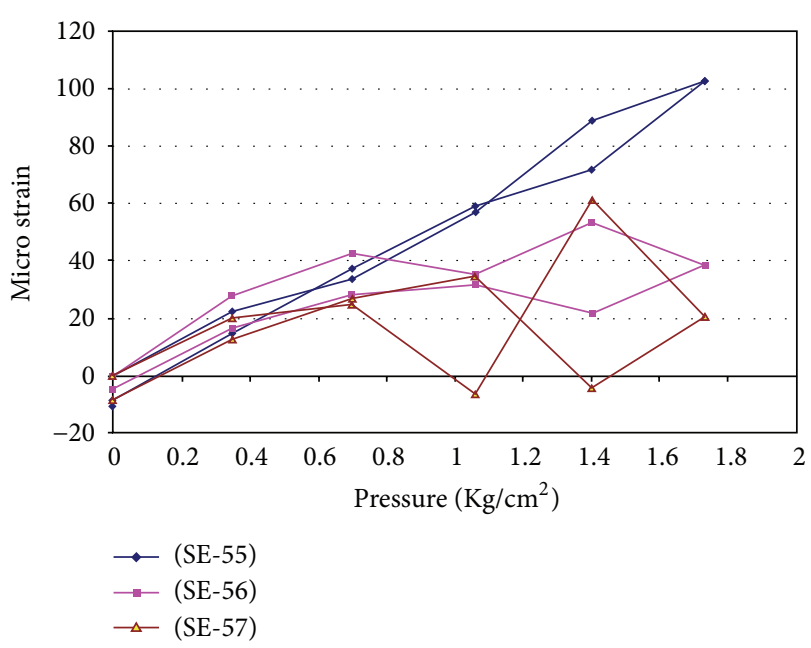

Figure 6: Micro strain of SMER's (SE-55, SE-56 \& SE-57) during ILRT.

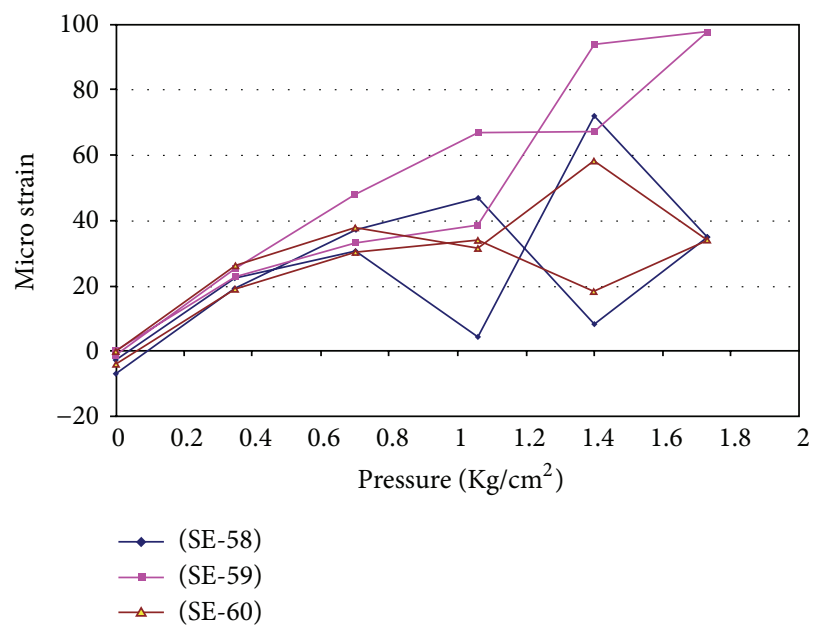

FIgure 7: Micro strain of SMER's (SE-58, SE-59 \& SE-60) during ILRT.

values of SE-55 and SE-59 at different pressure was found to be in increasing trend throughout the pressure test. This indicates that the response of the SMER was satisfactory. In the case of SE-56 to SE-58 and SE-60 the micro stain values were increasing. During pressuring it was witnessed in some SMERs decreased trend was followed. The response of the SMER sensibility was good. As the pressure increases the dome expanded. Gradually pressure increases the concrete side wall, and the dome expands. After sometimes there is a limit for steel and steel is reduced, and the side wall expands for further pressure.

Consequently the strain measurements for concrete SMER's for nuclear reactor contaminant during pressure test were from 0.0 to $1.73 \mathrm{~kg} / \mathrm{cm}^{2}$. All concrete SMER's the micro strain values at different pressure was found to be increasing trend throughout the pressure loading; this indicates that the response of the SMER's was satisfactory, and a linear trend was observed. 
TABLE 2: Strain Measurements from SMER's-Pressure from 0 to $1.73 \mathrm{~kg} / \mathrm{cm}^{2}$.

\begin{tabular}{|c|c|c|c|c|c|c|c|c|}
\hline \multirow{2}{*}{ SMER no. } & \multirow{2}{*}{ Location } & \multirow{2}{*}{ Legend } & \multicolumn{6}{|c|}{ Microstrain $(\mu \varepsilon)$ at pressure up $\left(\mathrm{kg} / \mathrm{cm}^{2}\right)$} \\
\hline & & & 0 & 0.35 & 0.7 & 1.06 & 1.4 & 1.73 \\
\hline \multicolumn{9}{|c|}{ On steel } \\
\hline SE-55 & Dome SG-1 opening, N-S & $(\mathrm{S} 1)$ & 0 & 22.7 & 33.7 & 57.2 & 88.9 & 102.7 \\
\hline SE-56 & Dome SG-1 opening, E-W & $(\mathrm{S} 1)$ & 0 & 28.1 & 42.6 & 35.4 & 53.5 & 38.6 \\
\hline SE-57 & Dome SG-1 opening, N-S & $(\mathrm{S} 2)$ & 0 & 20.1 & 24.8 & -6.5 & 61.2 & 20.8 \\
\hline SE-58 & Dome SG-1 opening, E-W & $(\mathrm{S} 2)$ & 0 & 22.5 & 30.8 & 4.3 & 72.1 & 34.8 \\
\hline SE-59 & Dome SG-1 opening, N-S & (S3) & 0 & 22.5 & 32.9 & 38.5 & 93.8 & 97.5 \\
\hline SE- 60 & Dome SG-1 opening, E-W & $(\mathrm{S} 3)$ & 0 & 26.2 & 37.7 & 31.6 & 58.1 & 33.9 \\
\hline \multicolumn{9}{|c|}{ On Concrete } \\
\hline SE-01 & Stressing gallery, $84.85 \mathrm{M}$, outer side $(\mathrm{N}), \mathrm{V}$ & A & 0 & 5.8 & 4.5 & 6.9 & 8.0 & 8.0 \\
\hline SE-02 & Stressing gallery, $84.85 \mathrm{M}$, inner side $(\mathrm{N}), \mathrm{V}$ & $\mathrm{B}$ & 0 & 6.6 & 6.6 & 12.7 & 17.2 & 17.7 \\
\hline SE-08 & ICW $(\mathrm{O}), 88.1 \mathrm{M},(\mathrm{S}), \mathrm{V}$ & $\mathrm{D}$ & 0 & 0.8 & -4.9 & -8.6 & -7.0 & -13.0 \\
\hline SE-25 & Ring beam, 133.5M, ICW (N), Cir & M & 0 & -9.1 & -14.4 & -16.6 & -34.7 & -28.1 \\
\hline
\end{tabular}

TABLE 3: Strain measurements from SMER's-pressure from 1.73 to $0 \mathrm{~kg} / \mathrm{cm}^{2}$.

\begin{tabular}{|c|c|c|c|c|c|c|c|c|c|}
\hline \multirow{2}{*}{ SMER no. } & \multirow{2}{*}{ Location } & \multirow{2}{*}{ Legend } & \multicolumn{7}{|c|}{ Microstrain $(\mu \varepsilon)$ at pressure down $\left(\mathrm{kg} / \mathrm{cm}^{2}\right)$} \\
\hline & & & 1.73 & 1.40 & 1.06 & 0.70 & 0.35 & 0 & $0(24 \mathrm{hrs})$ \\
\hline \multicolumn{10}{|c|}{ On steel } \\
\hline SE-55 & Dome SG-1 opening, N-S & $(\mathrm{S} 1)$ & 102.7 & 71.8 & 59.2 & 37.6 & 14.9 & -8.1 & -10.5 \\
\hline SE-56 & Dome SG-1 opening, E-W & $(\mathrm{S} 1)$ & 38.6 & 22.0 & 31.9 & 28.3 & 16.5 & -4.5 & -4.5 \\
\hline SE-57 & Dome SG-1 opening, N-S & $(\mathrm{S} 2)$ & 20.8 & -4.0 & 34.8 & 27.3 & 12.8 & -8.3 & -5.2 \\
\hline SE-58 & Dome SG-1 opening, E-W & $(\mathrm{S} 2)$ & 34.8 & 8.4 & 47.1 & 37.2 & 19.4 & -7.2 & -2.5 \\
\hline SE-59 & Dome SG-1 opening, N-S & (S3) & 97.5 & 67.0 & 66.8 & 47.9 & 25.4 & -1.2 & -0.4 \\
\hline SE-60 & Dome SG-1 opening, E-W & (S3) & 33.9 & 18.3 & 33.9 & 30.3 & 19.0 & -4.5 & -4.1 \\
\hline \multicolumn{10}{|c|}{ On Concrete } \\
\hline SE-01 & Stressing gallery, $84.85 \mathrm{M}$, outer side $(\mathrm{N}), \mathrm{V}$ & A & 8.0 & 3.8 & 4.3 & 1.4 & 0.0 & -7.0 & -23.3 \\
\hline SE-02 & Stressing gallery, $84.85 \mathrm{M}$, inner side $(\mathrm{N}), \mathrm{V}$ & $\mathrm{B}$ & 17.7 & 15.7 & 10.1 & 5.2 & 2.1 & -10.1 & -33.8 \\
\hline SE-08 & ICW (O), 88.1M, (S), V & $\mathrm{D}$ & -13.0 & -9.0 & -3.5 & 5.1 & 8.8 & 15.6 & 18.3 \\
\hline SE-25 & Ring beam, 133.5M, ICW (N), Cir & M & -28.1 & -25.9 & -19.7 & -2.3 & 14.9 & 24.1 & 23.3 \\
\hline
\end{tabular}

Table 3 depicts the strain measurements for steel SMER's at pressure 1.73 to $0.0 \mathrm{~kg} / \mathrm{cm}^{2}$; the micro stain values at depressurization were found to be in decreasing trend throughout the pressure down. Similarly strain measurements for concrete SMERs the micro strain values at pressure down were found to be a decreasing trend throughout the pressure test. This indicates that the response of the SMER's was satisfactory, and a linear trend was observed. In general the structural system has been sustained within its elastic limits. Temperature correction was carried for the three cycles, and average temperature correction was arrived.

\section{Conclusions}

The following broad conclusions were observed during ILRT for SMER's.

(1) The larger strain values of steel structures can be attributed to the temperature effect due to the open exposure to the sun light as these structures form the roof top of the containment and the ductility of steel which can take more strain.

(2) The data readings were collected for every 10 minutes for the entire test period.

(3) The performances of the various sensors were satisfactory, and the subsequent data analysis showed that the containment structure response was elastic during the loading and unloading stages and the test results were found to be in reasonable agreement.

(4) The Strain Measurements for Steel SMER's, pressure 0.0 to $1.73 \mathrm{~kg} / \mathrm{cm}^{2}$. SE-55 and SE-59 the steel SMER's the micro strain values at different pressure was found to be increasing trend throughout the pressure loading, this indicates that the response of the SMER's was satisfactory, a linear trend was observed.

(5) In the case of SE-56 to 58 and SE-60 the micro stain values were increasing during pressuring, and there 
was decreased trend in some cases was noticed. The response of the SMER's sensibility was good.

In the case of pressure down from 1.73 to $0.0 \mathrm{Kg} / \mathrm{cm}^{2}$ strain values for concrete and steel SMER's were found to be decreasing trend throughout the depressurization; this indicates that the response of the SMER's was satisfactory, and a linear trend was observed.

In general the structural system has been sustained within its elastic limits. The present paper describes the methodology, instrumentation line up, and software for continuous online strain data acquisition of structures. Measuring strain pattern on structures is vital to evaluate the health of forced members. They can be used for strain measurement even at elevated temperatures. The performance of strain gauges on concrete and steel containment structures of nuclear reactor is to assess the integrity and health of the containment structure.

\section{Conflict of Interests}

The authors declare that they have no conflict of interests.

\section{Acknowledgment}

The authors thank the Director of CECRI, Karaikudi, India, for his support to carry out this study.

\section{References}

[1] R. S. Bekowich, "Instrumentation in prestressed concrete containment structures," Nuclear Engineering and Design, vol. 8, no. 4, pp. 500-512, 1968.

[2] I. Thangamani, V. Verma, R. K. Singh, and A. K. Ghosh, "Thermal stress analysis of containment building in case of a Main Steam Line Break (MSLB)," Nuclear Engineering and Design, vol. 239, no. 9, pp. 1660-1672, 2009.

[3] http://ciks.cbt.nist.gov/bentz/nistir6551/node9.html.

[4] G. L. England, "Calculation of stresses in concrete ocean structures subjected to steady and time-varying temperatures, as influenced by creep," Applied Ocean Research, vol. 1, no. 1, pp. 33-41, 1979.

[5] R. D. Browne and R. Blundell, "The behaviour of concrete in prestressed concrete pressure vessels," Nuclear Engineering and Design, vol. 20, no. 2, pp. 429-475, 1972.

[6] Z. Sun, S. Liu, S. Lin, and Y. Xie, "Strength monitoring of a prestressed concrete containment with grouted tendons," Nuclear Engineering and Design, vol. 216, no. 1-3, pp. 213-220, 2002.

[7] D. M. Schultz, J. T. Julien, and H. G. Russell, “Tension tests of concrete containment wall elements," Nuclear Engineering and Design, vol. 77, no. 3, pp. 381-391, 1984.

[8] D. Yan and G. Lin, "Dynamic properties of concrete in direct tension," Cement and Concrete Research, vol. 36, no. 7, pp. 1371$1378,2006$.

[9] W. Chung, S. Kim, N.-S. Kim, and H.-U. Lee, "Deflection estimation of a full scale prestressed concrete girder using longgauge fiber optic sensors," Construction and Building Materials, vol. 22 , no. 3, pp. 394-401, 2008.
[10] C. G. Karayannis, M. E. Voutetaki, C. E. Chalioris, and G. M. Angeli, "Detection of flexural damage stages forRC beams using Piezoelectric sensors (PZT)," Smart Structures and Systems. In press.

[11] C. P. Providakis and M. E. Voutetaki, "Electromechanical admittance-based damage identification using Box-Behnken design of experiments," SDHM Structural Durability and Health Monitoring, vol. 3, no. 4, pp. 211-227, 2007.

[12] C. P. Providakis, D.-P. N. Kontoni, M. E. Voutetaki, and M. E. Stavroulaki, "Comparisons of smart damping treatments based on FEM modeling of electromechanical impedance," Smart Structures and Systems, vol. 4, no. 1, pp. 35-46, 2008.

[13] M. Frigione, M. A. Aiello, and C. Naddeo, "Water effects on the bond strength of concrete/concrete adhesive joints," Construction and Building Materials, vol. 20, no. 10, pp. 957-970, 2006.

[14] http://www.vishay.com/strain-gages/knowledge-base-list/ technotes-list.

[15] http://www.hbm.com/en/menu/support/.

[16] Reference book from HBM, An Introduction to Measurements using Strain Gauges, http://www.hbm.com/.

[17] http://zone.ni.com/devzone/cda/tut/p/id/3642.

[18] http://www.vishay.com/docs/11057/tn5071.pdf.

[19] ASTM E1237-93, Standard Guide for Installing Bonded Resistance Strain Gauges, 2003.

[20] C. S. Adderley, "Adhesive bonding," Materials and Design, vol. 9, no. 5, pp. 287-293, 1988.

[21] B. Wang, J. G. Teng, L. D. Lorenzis et al., "Strain monitoring of RC members strengthened with smart NSM FRP bars," Construction and Building Materials, vol. 23, no. 4, pp. 16981711, 2009.

[22] A. Flammini, P. Ferrari, E. Sisinni, D. Marioli, and A. Taroni, "Sensor interface: from field-bus to ethernet and internet," Sensors and Actuators A, vol. 101, no. 1-2, pp. 194-202, 2002. 

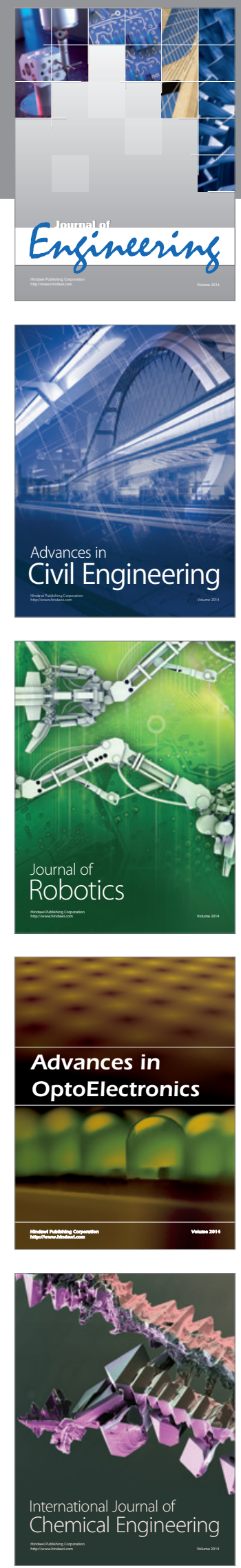

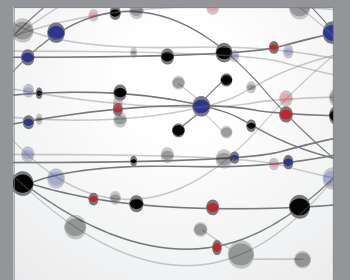

The Scientific World Journal
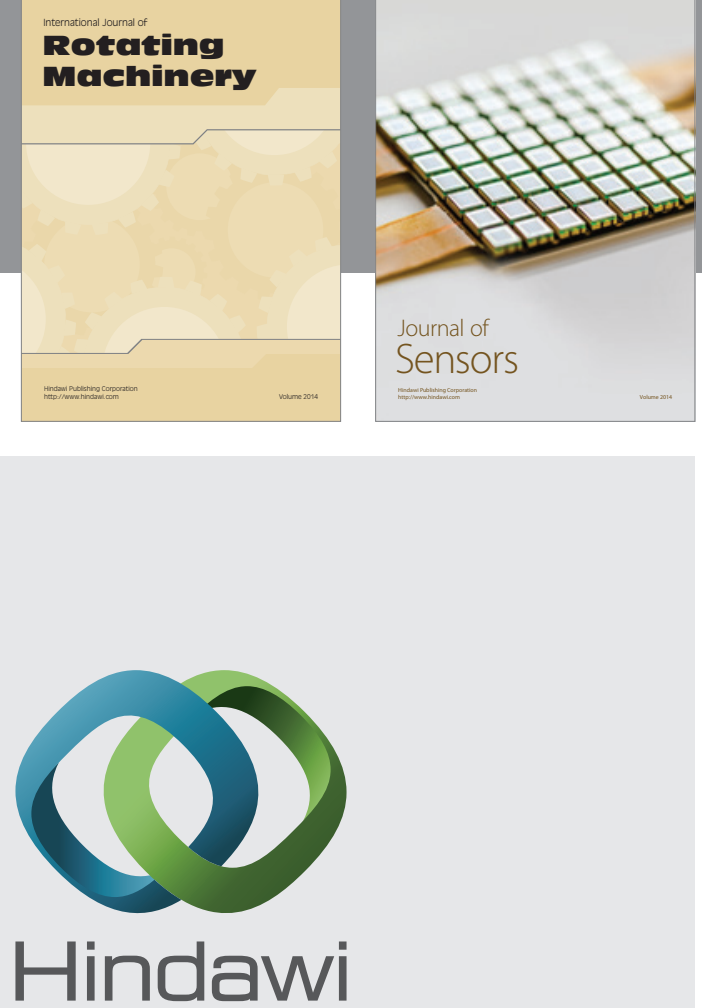

Submit your manuscripts at http://www.hindawi.com
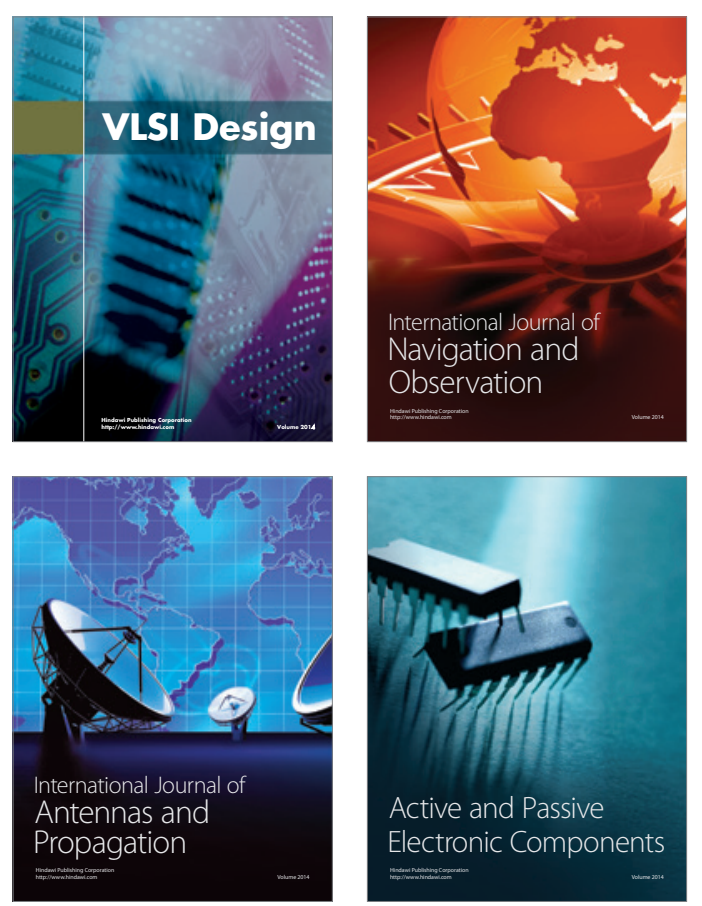
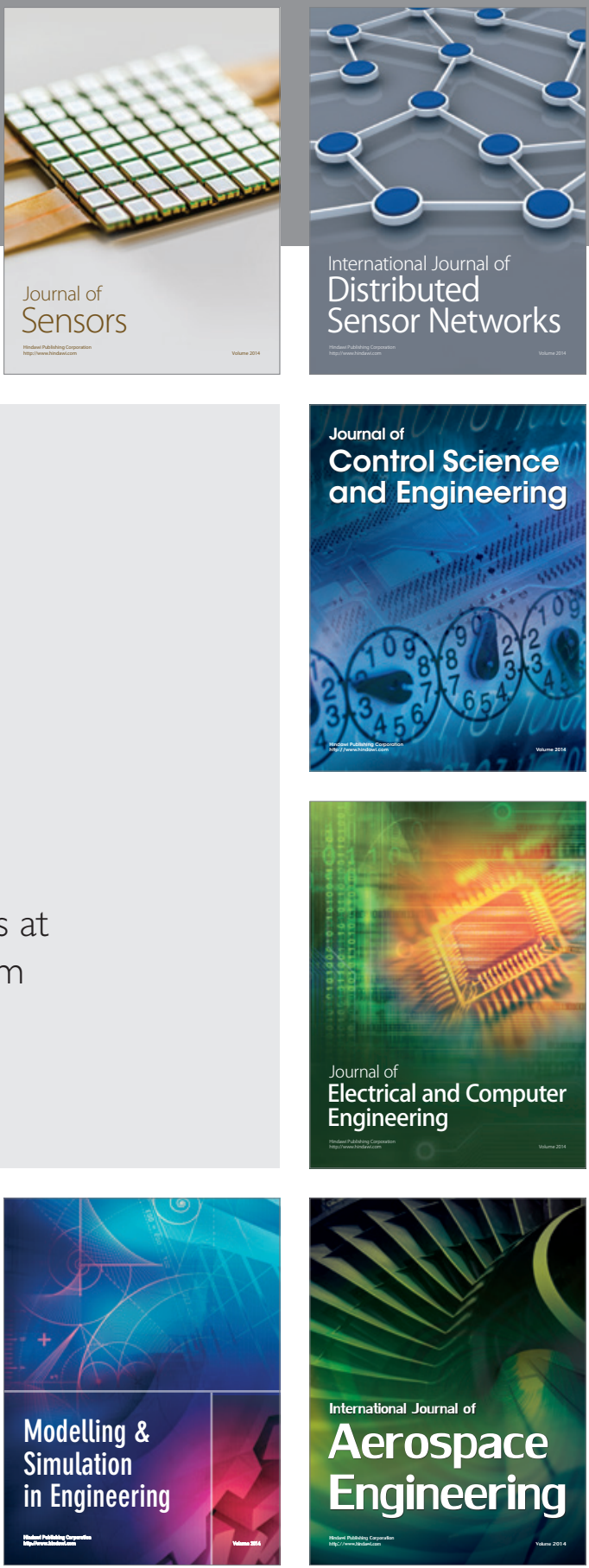

Journal of

Control Science

and Engineering
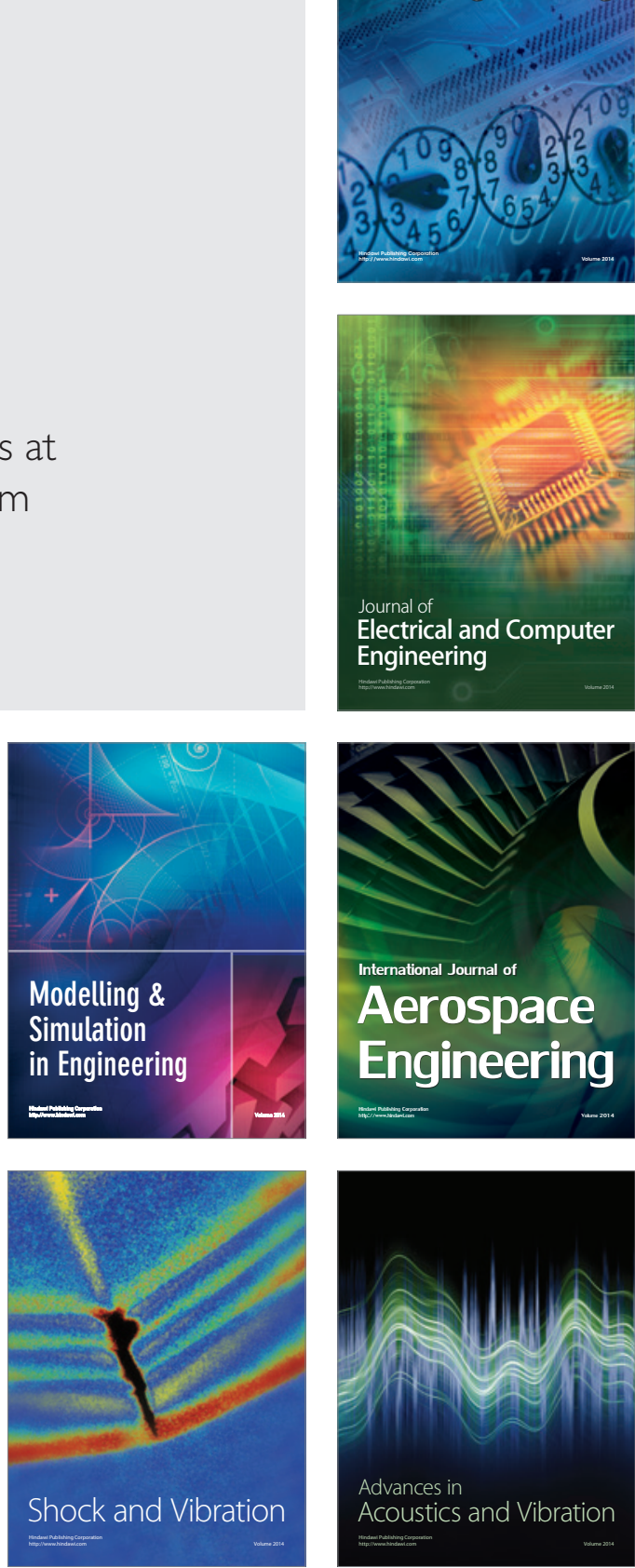